\title{
New patterns for geography field practice education based on location services
}

\author{
Ling Zhang a, b, c, Qian Jia ${ }^{\text {a }}$, Shaojun Liu a , Ling Ruan ${ }^{\text {a }}$, Yi Long a, b, c* \\ ${ }^{a}$ Key Laboratory of Virtual Geographic Environment (Nanjing Normal University), Ministry of Education, Nanjing, 210023, China \\ lingzhang.sky@gmail.com \\ ${ }^{b}$ State Key Laboratory Cultivation Base of Geographical Environment Evolution (Jiangsu Province), Nanjing, 210023, China \\ ${ }^{c}$ Jiangsu Center for Collaborative Innovation in Geographical Information Resource Development and Application, Nanjing, \\ 210023, China \\ * Corresponding author
}

Keywords: Geography field practice, Teaching patterns, LBS, Field practice assistant

\begin{abstract}
:
Geography field practice plays an important role in the training of professionals for geographical science. Many universities in China even entire world with geography-related majors have planned it into the teaching program as a core of practical course. However, in the aspect of teaching pattern, it is still based on the traditional indoctrination teaching method, which is mainly taught by teachers and accepted by students. There are some problems in this teaching pattern, such as the poor practice quality due to the serious imbalance between teachers and students. It is urgent to adopt more powerful information technology to improve the traditional teaching pattern by starting from the practice process.
\end{abstract}

At present, there are few studies both on geography field practice patterns and its informatization. The informative teaching pattern for geography field practice has not been proposed yet. The field practice teaching activities are closely related to the spatial location, so the rapid development of geographic information technology with LBS as the core brings an opportunity to solve the problems existing in the traditional pattern. Therefore, this study makes full use of the support advantages of location service to the geography field practice process, builds geography field practice patterns based on LBS, and promotes the new patterns into practical application by designing the Lushan geography field practice system. Based on the above ideas, this paper has mainly completed the following aspects:

First, new patterns for geography field practice based on LBS are proposed. Based on the analysis of the traditional geography field practice process and related supporting technologies, the "dominant-subject" teaching theory is used as the theoretical basis for the pattern construction. In order to the transforming of the subject in geography field practice from teachers to students, GIS and LBS technologies are used to support it. Three geography field practice patterns, teacher-dominated, cooperated and student-dominated patterns, are proposed, and for each pattern, a typical spatial scenario is given. New patterns can reflect the characteristics of online-offline collaboration, teacher-student collaboration, and process-result collaboration.

Second, implementation methods for above three patterns are designed. Lushan, China is selected as a typical research area for the application of geography field practice patterns. The application requirements of interns, tasks and processes for geographic information and location services are analyzed. The mechanism and implementation of LBS for three patterns are discussed. In the teacher-dominated pattern, the real-time position of teachers and students can be used to know the practicing status of students and provide support for the rational control of field practice progress. In the cooperated pattern, geography field practice can be effectively carried out by location-based explanation services, geographic information inquiry and real-time communication services between teachers and students. In the studentdominated pattern, points and routes inquiries with location-based and spatial analysis, as well as records of practicing trajectories and process, are important aids for students to carry out independent inquiry and for teachers to evaluate students' practice results. In addition, this thesis designs the functional framework of the LuShan Geographic Field Practice Platform, and it is a solid foundation to apply new patterns in real scenes.

Third, the application effects of the new practice patterns in Lushan geography field practice are analyzed. Based on the application of the Lushan geography field practice platform, online Q\&A, practice points works and practice trajectory data during the practice process are analyzed. It can find the areas where problems are concentrated in, and it also can assess the completion of the practice task. Finally, the reasonable evaluation of the geography field practice effects for each pattern is given, and the improvement suggestions for the person control, task arrangement and schedule management of the follow-up field practice are also provided. 